\title{
INTRARENAL FOREIGN BODY PRESENTING AS A RENAL CALCULUS
}

\author{
Rafael Ferreira Coelho, Anuar Ibrahim Mitre, Miguel Srougi
}

\section{INTRODUCTION}

Retained surgical sponges, so called textilomas, are rare complications after abdominal surgeries. The estimated incidence is approximately 1 per 1,000-1,500 surgical operations ${ }^{1}$. However the true incidence is difficult to determine mainly because of underreporting due to medical legal issues. In a retroperitoneal location these textilomas represent less than $17 \%$ of abdominal locations and reports of renal or perirenal textilomas are scarce. The pre-operative diagnosis is difficult because they mimic tumors, abscesses, pseudo-cysts or hematomas. Clinical manifestations may occur early or late after surgery, depending on the type of inflammatory reaction induced ${ }^{2,3,4}$. Radiology may contribute to the pre-operative diagnosis, especially when a radio-opaque marker is obvious, whereupon, conventional radiography may then allow for an accurate diagnosis. Otherwise, certain characteristic signs may be sought with ultrasound, computed tomography $(\mathrm{CT})$, or magnetic resonance imaging (MRI) ${ }^{5}$.

We describe a case of surgical gauze retained in the renal pelvis after an open renal surgery presenting as a renal calculus.

\section{CASE REPORT}

A 45-year-old female patient presented to our service with complaint of long-standing right lumbar pain. The patient had undergone open renal surgery in another institution 4 years before for renal calculus treatment, with an uneventful recovery. No information about the previously performed surgical procedure is available. On admission, physical examination showed a right lombotomy incision scar. The patient was evaluated with a plain film of the abdomen and found to have two calcifications lateral to the right transverse process of the L2-L3 vertebrae, compatible with a renal calculi (Fig.1). An intravenous urogram showed both radiopaque images inside the collecting sys-

Department of Urology, Hospital das Clínicas, Faculty of Medicine, University of São Paulo, São Paulo, Brazil.

Email: coelhouro@yahoo.com.br tem of the right kidney, confirming the diagnosis of recurrent stone disease (Fig. 2). A percutaneous nephrolitotomy was performed and surprisingly after an initial pelvic stone fragmentation with the ultrasound device progression stopped and the possibility of a calcified surgical gauze was considered. A 5mm laparoscopic scissor was introduced through the working channel of nephroscope and the gauze was progressively cut and removed in small pieces. The gauze had no radiopaque markers (Fig. 3). The postoperative period was uneventful. Abdominal plain film and ultrasound after surgery showed no residual calculus and the patient was pain free.

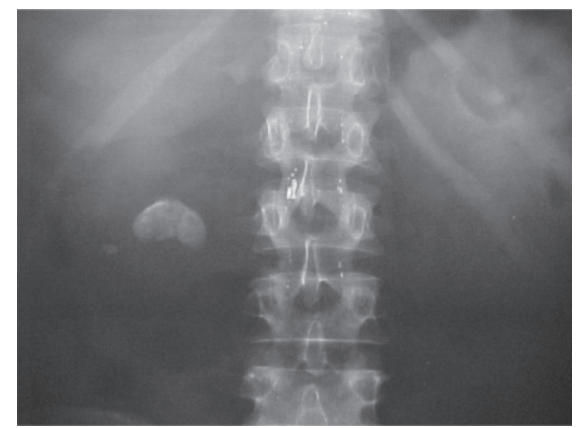

Figure 1 - Plain X-ray demonstrating arcuate-shaped calcification at right flank compatible with renal calculus.

\section{DISCUSSION}

Kidney foreign bodies are very rare entities and one of the most common routes through which kidneys may be reached is the gastrointestinal tract. Such foreign bodies are typically lacerating objects in the food (such as fishbone, needles, pins, hairgrips, toothpicks). ${ }^{2}$ Surgical sponges or gauzes left after renal surgery are scarcely reported in literature and in an intrarenal location they are even rarer. ${ }^{3-5}$ However, such retained textilomas are obviously underreported mainly because of medical and legal problems. Presentation includes purulent cutaneous fistulae, renal and perirenal pseudotumors, and renal calculus formation. ${ }^{3-11}$ These foreign bodies can also remain asymptomatic for years and a proper follow-up with radiological evaluation can assist in the proper diagnosis previously to the ap- 


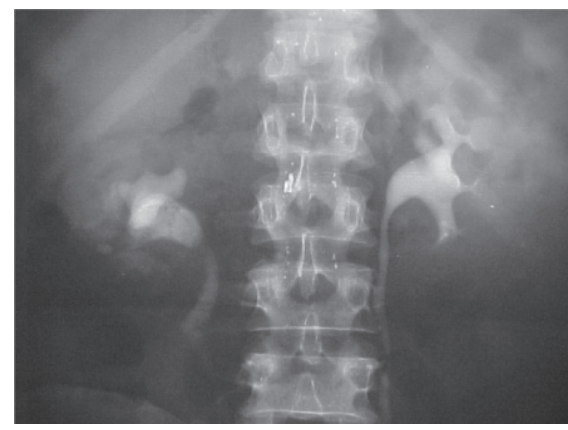

Figure 2 - Intravenous urogram after contrast enhancement demonstrating an intrarenal pelvic calculus.

pearance of symptoms. ${ }^{4} \mathrm{~A}$ high index of suspicion is important when evaluating a patient with previous surgery. In our case the diagnosis was not suspected preoperatively because the first surgery was performed in another institution without postoperative follow-up and the foreign body had no radiopaque markers. The typical radiographic appearance of the retained sponge on computed tomography and magnetic resonance imaging has been previously described and these image studies can contribute to the preoperative diagnosis. ${ }^{12}$ The retained sponge may have a whorl-like appearance on CT and MRI, with increased intensity in T2-weighted, compared to T1-weighted images. ${ }^{4}$ In cases of recurrent calculus, following a previous open kidney surgery, CT or MRI can be more informative than urography and should be considered in the preoperative evaluation. However, CT and MRI cannot unequivocally distinguish a retained foreign body from other urologic diseases like abscesses, tumors and calculi. In countries where radiopaque markers are normally used, simple plain radiographs can make the diagnosis. ${ }^{5}$

Surgical or endoscopic removal of the foreign body is mandatory in view of the high complication rate. Some pre-

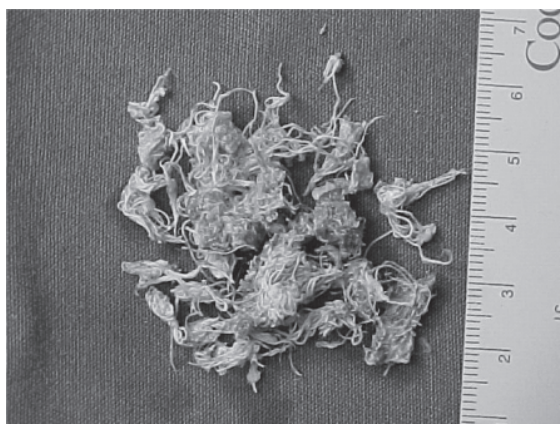

Figure 3 - Calcified surgical gauze fragments removed by percutaneous approach.

vious reports including removal of the foreign body by percutaneous nephrostomy or by endoscopic maneuvers were described. Removal of migrated ureteral stents has been accomplished percutaneously through the kidney using a grasping forceps and endoscopically using a Fogarty catheter, a forceps or a dormia basket. ${ }^{13,14}$ However, to our knowledge, the use of a laparoscopic scissor through the working channel of nephroscope to cut and removed a calcified surgical gauze has not been previously described. We believe that this is a simple and effective approach to the removal intrarenal textilomas avoiding another open renal surgery.

Prevention of retained surgical sponges and gauzes is clearly better than the treatment of the complications, and strict safeguards can ensure such prevention. Compresses should be used one by one mounted on a forceps. Before closing the incision, the surgeon should completely explore the whole abdominal cavity. All the appliances and surgical sponges should be counted by two or more nurses, the circulating and the scrub nurses. Small sponges should be avoided during laparotomy and only sponges with radiopaque filaments should be used. A plain X-ray film should be taken before finishing any operation.

\section{REFERENCES}

1. Jason RS, Chisolm A, Lubetsky HW. Retained surgical sponge simulating a pancreatic mass. J Natl Med Assoc 1979;71:501-3.

2. Van Ophoven A, de Kernion JB: Clinical management of foreign bodies of the genitourinary tract. J Urol 2000,164: 274-287.

3. Ballesteros Sampol FF, Alameda Quitllet F, Pares Puntas ME: 3 rare cases of textiloma after renal surgery. Review of the literature. Ballesteros. Arch Esp Urol 2002, 55: 25-29.

4. Ben Meir D, Lask D, Koren R, Livne PM: Intrarenal foreign bogy presenting as a solid tumor. Urology 2003, 61: 1035-1035.

5. Bellin MF, Hornoy B, Davy-Miallou C et al: Perirenal Textiloma: MR and serial CT appearance. Eur Radio 1998, 8: 57-59.

6. Rebassa Llull Mj, Munoz Velez D, Hidalgo Pardo F et al: Foreign body as renal pseudotumor in a patient with renal polycystic kidney. Arch Esp Urol 2000, 53:831-833

7. Fiorelli C, Menghetti I, Tripitteli A et al: Renal pseudotumors caused by retained pararenal surgical sponges. Rays 1984, 10: 49-52.

8. Uribe CA, Castellanos RI, Velez A, Florez F, Gaviria F: Unusual cause of a mass in the superior pole of the kidney: report of a case. Arch Esp Urol 2002, 55: 958-959.
9. Rebassa Llull MJ, Munoz Velez D, Hidalgo Pardo F, Gutierrez SanzGadea C, Palmer Sancho J, Mus Malleu A, Torrens Darder I, Ozonas Moraques M: Foreign body as renal pseudotumor in a patient with renal polycystic kidney. Arch Esp Urol 2000, 53: 831-833.

10. Touiti D, Paparel P, Deligne E, Dawahra M, Colombel M, Martin X, Gelet A: Retroperitoneal foreign body mimicking pararenal tumor. Ann Urol 2001, 35: 151-153.

11. Pascual Regueiro D, Mallen Mateo E, Allue Lopez M, Garcia de Jalon Martinez A, Roncales Badal A, Rioja Sanz LA: Foreign body simulating kidney tumour. Actas Urol Esp 2004, 28: 390-392.

12. Kuwashima S, Yamoto M,Fujioka M, et al: Mr findings of surgically retained sponges and towels: report of two cases. Radiol Med 1993 11:98-101.

13. Grossman I, Pollack HM, Banner MP et al. Endoscopic removal of intrarenal foreign body using dormia stone basket. Urology 1982, 24 (4);458-60.

14. Meranz SG, Pollack HM, Banner MP. The use of grasping forceps in the upper urinary tract: technique and radiologic implications. Radiology 1982, 144:171. 